\title{
The Forgotten Variable of Shear Stress in Mitral Annular Calcification: Whole Blood Viscosity
}

\author{
Elif Hande Ozcan Cetin Mehmet Serkan Cetin Ugur Canpolat Erol Kalender \\ Serkan Topaloglu Dursun Aras Sinan Aydogdu \\ Cardiology Clinic, Yuksek Ihtisas Training and Research Hospital, Ankara, Turkey
}

\section{Key Words}

Mitral valve calcification - Shear stress · Blood viscosity

\section{Abstract}

Objective: The aim of this research was to assess the relationship between mitral annular calcification (MAC) and whole blood viscosity (WBV). Subjects and Methods: A total of 184 patients with MAC and 133 patients without MAC were enrolled in the study. The WBV was calculated with a confirmed formulation using the hematocrit and total plasma protein at a low shear rate (LSR) and high shear rate (HSR). Early diastolic mitral annular velocity (Ea) and late diastolic mitral annular velocity $(\mathrm{Aa})$ were measured using pulse Doppler tissue echocardiography. Pearson's correlation analysis was performed to assess the relationship between WBV and mitral annular motion velocities. The effects of different variables on the occurrence of MAC were assessed in univariate and multivariate logistic regression analysis. Results: In patients with MAC, WBV values were significantly higher at HSR $\left(18.04 \pm 0.84\right.$ vs. $\left.17.25 \pm 0.96208 \mathrm{~s}^{-1}, \mathrm{p}<0.001\right)$ and at LSR (78.0 \pm 14.2 vs. $\left.61.9 \pm 17.10 .5 \mathrm{~s}^{-1}, \mathrm{p}<0.001\right)$. The WBV at
HSR and LSR were significantly correlated with $\mathrm{Ea}(r=-0.477$, $p<0.001 ; r=-0.385, p<0.001$, respectively) and $A a(r=$ $-0.544, p<0.001 ; r=-0.323, p<0.001$, respectively). Multivariate analysis showed that WBV of both shear rates was an independent predictor of MAC. Using the ROC curve, a cut-off value of 70.1 for WBV at LSR had a sensitivity of $83.7 \%$ and a specificity of $73.7 \%$ (AUC $0.785, p<0.001$ ) and a WBV cut-off value of 17.5 at HSR had a sensitivity of $79.6 \%$ and a specificity of $71.4 \%$ (AUC $0.761, p<0.001$ ) for the prediction of MAC. Conclusion: Patients with MAC had significantly higher WBV, which independently predicted the presence of MAC. WBV had an inverse correlation with mitral annular motion velocities, indicating that a higher WBV may lead to greater limitation in annular motion and, thus, more calcification.

(c) 2015 S. Karger AG, Basel

\section{Introduction}

Mitral annular calcification (MAC) is a chronic and degenerative process with progressive calcium deposition along and beneath the mitral valve annulus [1]. As a frequent echocardiographic finding, MAC is associated with

\begin{tabular}{ll}
\hline KARGER 125:s & $\begin{array}{l}\text { () 2015 S. Karger AG, Basel } \\
1011-7571 / 15 / 0245-0444 \$ 39.50 / 0 \quad \text { Karger }\end{array}$ \\
$\begin{array}{l}\text { E-Mail karger@karger.com } \\
\text { www.karger.com/mpp }\end{array}$ & $\begin{array}{l}\text { This is an Open Access article licensed under the terms of the } \\
\text { Creative Commons Attribution-NonCommercial 3.0 Un- } \\
\text { ported license (CC BY-NC) (www.karger.com/OA-license), } \\
\text { applicable to the online version of the article only. Distribu- } \\
\text { tion permitted for non-commercial purposes only. }\end{array}$
\end{tabular}

Elif Hande Ozcan Cetin, MD

Cardiology Clinic, Yuksek Ihtisas Education and Research Hospital Kizilay Street

TR-06100 Ankara (Turkey)

E-Mail dr.elifhande@gmail.com 
systemic calcific atherosclerosis with similar risk factors [2]. Also, both pathologies are initiated by an endothelial insult in which shear stress might have a significant role [3]. Because of this relationship, previous studies suggest that MAC might be a form of atherosclerotic process [4]. Beyond a visual entity, MAC has a restrictive effect on mitral annular motion. It has been postulated that mitral annular motion velocities have a negative correlation with the severity of MAC [5].

Increased whole blood viscosity (WBV), as an important but neglected parameter of Virchow's triad, can aggravate endothelial disruption at the foci of enhanced mechanical stress, such as at the junction between the mitral valve annulus and left ventricular myocardium [6]. WBV can be simply extrapolated with a confirmed formula using the hematocrit (HCT) and total protein levels [7].

We hypothesized that increased WBV might have a relationship with the occurrence and severity of MAC. In this study, we aimed to compare WBV values of patients with and without MAC and assess the correlation of WBV with mitral annular motion velocities.

\section{Subjects and Methods}

\section{Study Population}

A total of 317 patients $[\mathrm{n}=184$ with $\mathrm{MAC}(+)$ and $n=133$ without MAC(-)] who underwent echocardiographic evaluation in our Echocardiography Laboratory between January 2013 and January 2014 were prospectively included in this study. Exclusion criteria were: patients with hematological diseases (including anemia), oncological, active or chronic infectious or inflammatory disease, left ventricular ejection fraction $<50 \%$, renal or hepatic insufficiency, presence of structural deformity in the mitral annulus, rheumatic heart disease, prosthetic heart valves, aortic calcification, hyperparathyroidism, hypercalcemia, hyperphosphatemia, congenital heart disease, severe valvular disease and autoimmune disease.

Hypertension was determined if the patient had a physicianconfirmed diagnosis and was taking antihypertensive medication, or if the patient had an untreated blood pressure of $>140 / 90 \mathrm{~mm}$ Hg. Diabetes mellitus was defined as the use of antidiabetic drugs and a fasting blood glucose $>126 \mathrm{mg} / \mathrm{dl}$. Hyperlipidemia was identified in patients with total cholesterol $>200 \mathrm{mg} / \mathrm{dl}$, low-density lipoprotein $>130 \mathrm{mg} / \mathrm{dl}$, triglyceride levels $>150 \mathrm{mg} / \mathrm{dl}$ and receiving lipid-lowering drugs. The study protocol was approved by the Institutional Ethics Committee and written informed consent was obtained from all subjects.

\section{Transthoracic Echocardiography}

All study participants underwent echocardiographic examinations using Vivid 7 Pro (GE VingMed Ultrasound, Horten, Norway). Complete 2D echocardiography, including a Doppler examination, was obtained in all standard views (parasternal long-axis, parasternal short-axis, apical 4-chamber and apical 2-chamber views). Transthoracic echocardiography was performed by experienced cardiologists (E.H.O.C., M.S.C., E.K.) who were blinded to each participant's clinical status. The left ventricular ejection fraction was appraised with the modified Simpson technique. Left atrial and ventricular dimensions were measured by M-mode echocardiography in the parasternal long-axis view using the criteria of the American Society of Echocardiography.

The MAC was defined as the presence of an echodense tracing visualized throughout the systole and diastole, distinguishable from the posterior mitral leaflet and located anterior and parallel to the posterior LV wall (M-mode echocardiography) and an intense, $\geq 2$-mm-wide echocardiographic structure (when measured from the leading anterior to the trailing posterior edge at its greatest width) [8].

\section{Pulsed Doppler Tissue Imaging}

Pulsed Doppler tissue echocardiography was performed by activating the Doppler tissue imaging function with the same echocardiographic machine. In the apical 4-chamber view, the sample volume was determined at the mitral annulus in the left ventricular posterior wall. The wall motion velocity patterns were evaluated and the peak early (Ea) and late (Aa) diastolic annular velocities were measured.

\section{Blood Sampling}

Peripheral blood samples were drawn via the antecubital vein after a 12-hour overnight fast and collected in yellow biochemistry tubes without anticoagulant for biochemical tests and in tubes with EDTA for hematological tests. The erythrocyte count, hemoglobin, HCT and white blood cell count were measured using the automated hematology analyzer XE-1200 (Sysmex, Kobe, Japan). The biochemical measurements were determined using a molecular analyzer (Roche Diagnostics, Manheim, Germany).

\section{Extrapolation of $W B V$}

WBV was calculated from the HCT (\%) and plasma protein concentration (TP; g/l) at a low shear rate (LSR; $0.5 \mathrm{~s}^{-1}$ ) and a high shear rate (HSR; $208 \mathrm{~s}^{-1}$ ) by the validated equation of de Simone et al. [7, see also 9]:

HSR: WBV $\left(208 \mathrm{~s}^{-1}\right)=(0.12 \times \mathrm{HCT})+0.17 \times(\mathrm{TP}-2.07)$, LSR: WBV $\left(0.5 \mathrm{~s}^{-1}\right)=(1.89 \times \mathrm{HCT})+3.76 \times(\mathrm{TP}-78.42)$.

In their series of 'WBV Assessment Issues', Nwose and Richards [9] recommended the extrapolation of WBV from HCT in percent (\%) and TP in grams per liter $(\mathrm{g} / \mathrm{l})$ as the best appropriate approach, especially for estimating WBV in LSR.

\section{Statistical Analysis}

Statistical analysis was performed using SPSS 20.0 (SPSS Inc., Chicago, Ill., USA). Continuous data were presented as the median or mean \pm SD. The Kolmogorov-Smirnov test was used to assess the distribution pattern. Categorical variables were summarized as the number and percentage. Comparisons between the two groups were performed with Student's t test for continuous variables and the $\chi^{2}$ test or Fisher's exact test for categorical variables. Pearson's correlation analysis was performed to assess the correlation of WBV and mitral annular motion velocities (Ea, Aa). We analyzed the effects of different variables on the occurrence of MAC in univariate analysis and determined the variables with an unadjusted 
$\mathrm{p}$ value $<0.1$ as potential risk markers and included them in the full model. We composed the model by using backward elimination at multivariate logistic regression analysis, and we eliminated potential risk markers by using likelihood ratio tests. We evaluated the predictiveness of WBV for occurrence of MAC with receiver operating characteristic (ROC) analysis. A p value $<0.05$ was considered statistically significant.

\section{Results}

The baseline characteristics and laboratory findings of the study groups are given in table 1 . The study groups were similar in regard to various baseline parameters except for lower high-density lipoprotein cholesterol levels $(\mathrm{p}=0.002)$ and higher rates of hypertension $(\mathrm{p}=0.041)$ in the $\mathrm{MAC}(+)$ group. In the $\mathrm{MAC}(+)$ group, WBV values were significantly higher for HSR (18.04 \pm 0.84 vs. $\left.17.25 \pm 0.96208 \mathrm{~s}^{-1}, \mathrm{p}<0.001\right)$ and for LSR $(78.0 \pm 14.2$ vs. $61.9 \pm 17.10 .5 \mathrm{~s}^{-1}, \mathrm{p}<0.001$; table 2).

In the correlation analysis of mitral annular motion velocities with WBV, WBV at HSR and LSR were significantly correlated with $\mathrm{Ea}(\mathrm{r}=-0.477, \mathrm{p}<0.001 ; \mathrm{r}=-0.385$, $\mathrm{p}<0.001$, respectively $)$ and $\mathrm{Aa}(\mathrm{r}=-0.544, \mathrm{p}<0.001 ; \mathrm{r}=$ $-0.323, \mathrm{p}<0.001$, respectively; fig. 1,2$)$. WBV for both LSR and HSR were found to be independent predictors for the presence of MAC (WBV at LSR: OR 1.071, 95\% CI 1.052-1.091, $\mathrm{p}<0.001$; WBV at HSR: OR 3.118, 95\% CI $2.202-4.415, \mathrm{p}<0.001$; table 3 ). In the ROC curve analysis, a WBV cut-off value of 70.1 at LSR had a sensitivity of $83.7 \%$ and a specificity of $73.7 \%$ for the prediction of MAC (AUC 0.785, p < 0.001) and a WBV cut-off value of 17.5 at HSR had a sensitivity of $79.6 \%$ and specificity of $71.4 \%$ for the prediction of MAC (AUC $0.761, \mathrm{p}<0.001$; fig. 3).

\section{Discussion}

In this study, WBV values were significantly higher at LSR and HSR in the MAC(+) group than the MAC(-) group. Also, WBV at both LSR and HSR demonstrated significant negative correlations with mitral annular motion velocities. WBV values were independent predictors of the presence of MAC after adjusting for other previously known risk factors for MAC, including hypertension [10]. Being a major component of shear stress, WBV extrapolated readily with the validated formula using HCT and total protein. Furthermore, it seemed to be a useful and easily available predictor of MAC, and it might also be used as a screening method for atherosclerotic diseases.
Table 1. Baseline characteristics and laboratory findings of the study groups $(\mathrm{n}=317)$

\begin{tabular}{|c|c|c|c|}
\hline Variables & $\begin{array}{l}\operatorname{MAC}(+) \\
(\mathrm{n}=184)\end{array}$ & $\begin{array}{l}\operatorname{MAC}(-) \\
(n=133)\end{array}$ & $\begin{array}{l}\mathrm{p} \\
\text { value }\end{array}$ \\
\hline \multicolumn{4}{|l|}{ Clinical parameters } \\
\hline Age, years & $69.1 \pm 5.2$ & $68.0 \pm 4.6$ & 0.070 \\
\hline Male gender & $95(51.6)$ & $71(53.4)$ & 0.758 \\
\hline Hypertension & $68(37)$ & $36(27.1)$ & 0.041 \\
\hline Diabetes mellitus & $42(22.8)$ & $28(21.1)$ & 0.407 \\
\hline Hyperlipidemia & $43(23.4)$ & $29(21.8)$ & 0.425 \\
\hline Current smokers & $37(20.1)$ & $24(18)$ & 0.646 \\
\hline $\mathrm{BMI}$ & $23.8 \pm 3.1$ & $24.1 \pm 2.7$ & 0.206 \\
\hline LVEF, \% & $57.4 \pm 4.5$ & $58.6 \pm 3.7$ & 0.098 \\
\hline \multicolumn{4}{|l|}{ Medications } \\
\hline ASA & $47(25.5)$ & $39(29.3)$ & 0.455 \\
\hline$\beta$-Blocker & $28(15.2)$ & $25(18.8)$ & 0.399 \\
\hline Ace inhibitor/ARB & $52(28.3)$ & $37(27.8)$ & 0.931 \\
\hline Statins & $33(17.9)$ & $19(14.3)$ & 0.387 \\
\hline Ca-channel blocker & $15(8.2)$ & $9(6.8)$ & 0.645 \\
\hline \multicolumn{4}{|l|}{ Laboratory parameters } \\
\hline Hemoglobin, g/dl & $14.4 \pm 1.7$ & $14.1 \pm 1.6$ & 0.146 \\
\hline $\mathrm{HCT}, \%$ & $42.8 \pm 4.8$ & $42.6 \pm 5.1$ & 0.820 \\
\hline $\mathrm{WBC}, \times 10^{3} \mu \mathrm{l}$ & $7.2 \pm 1.8$ & $7.1 \pm 1.8$ & 0.876 \\
\hline Neutrophils, $\times 10^{3} / \mu \mathrm{l}$ & $4.8 \pm 1.7$ & $4.9 \pm 1.3$ & 0.430 \\
\hline Lymphocytes, $\times 10^{3} / \mu \mathrm{l}$ & $1.4 \pm 0.29$ & $1.5 \pm 0.38$ & 0.080 \\
\hline Platelets, $\times 10^{3} / \mu \mathrm{l}$ & $227.1 \pm 110.2$ & $231.6 \pm 111.3$ & 0.729 \\
\hline Glucose, mg/dl & $97.03 \pm 35.2$ & $94.00 \pm 32.0$ & 0.083 \\
\hline Urea, mg/dl & $40.9 \pm 15.0$ & $36.3 \pm 11.4$ & 0.119 \\
\hline Serum creatinine, $\mathrm{mg} / \mathrm{dl}$ & $1.2 \pm 0.4$ & $1.1 \pm 0.4$ & 0.679 \\
\hline Total protein, g/l & $74.2 \pm 6.3$ & $73.9 \pm 5.3$ & 0.688 \\
\hline Serum albumin, $\mathrm{mg} / \mathrm{dl}$ & $4.5 \pm 0.4$ & $4.4 \pm 0.4$ & 0.845 \\
\hline Total cholesterol, mg/dl & $173 \pm 80.4$ & $168.5 \pm 76.5$ & 0.592 \\
\hline LDL cholesterol, mg/dl & $120.7 \pm 42.1$ & $118.4 \pm 36.7$ & 0.656 \\
\hline HDL cholesterol, mg/dl & $38.6 \pm 12.2$ & $43.4 \pm 12.6$ & 0.002 \\
\hline Triglycerides, mg/dl & $149.9 \pm 64.3$ & $139.8 \pm 59.1$ & 0.255 \\
\hline
\end{tabular}

Values represent mean \pm SD or $\mathrm{n}(\%)$. ASA $=$ Acetylsalicylic acid; $\mathrm{ACE}$ = angiotensin-converting enzyme; $\mathrm{ARB}=$ angiotensin receptor blocker; $\mathrm{Ca}=$ calcium; $\mathrm{WBC}=$ white blood cell count; $\mathrm{HDL}=$ high-density lipoprotein; $\mathrm{LDL}=$ low-density lipoprotein; $\mathrm{LVEF}=$ left ventricular ejection fraction.

Table 2. Comparison of WBV parameters of the study groups

\begin{tabular}{llll}
\hline Variables & $\begin{array}{l}\text { MAC(+) } \\
(\mathrm{n}=184)\end{array}$ & $\begin{array}{l}\text { MAC(-) } \\
(\mathrm{n}=133)\end{array}$ & p value \\
\hline WBV at HSR, 208 s & $18.04 \pm 0.84$ & $17.25 \pm 0.96$ & $<0.001$ \\
WBV at LSR, 0.5 s & $77.98 \pm 14.20$ & $61.88 \pm 17.18$ & $<0.001$ \\
\hline
\end{tabular}

Values represent mean $\pm \mathrm{SD}$.
Ozcan Cetin et al. 

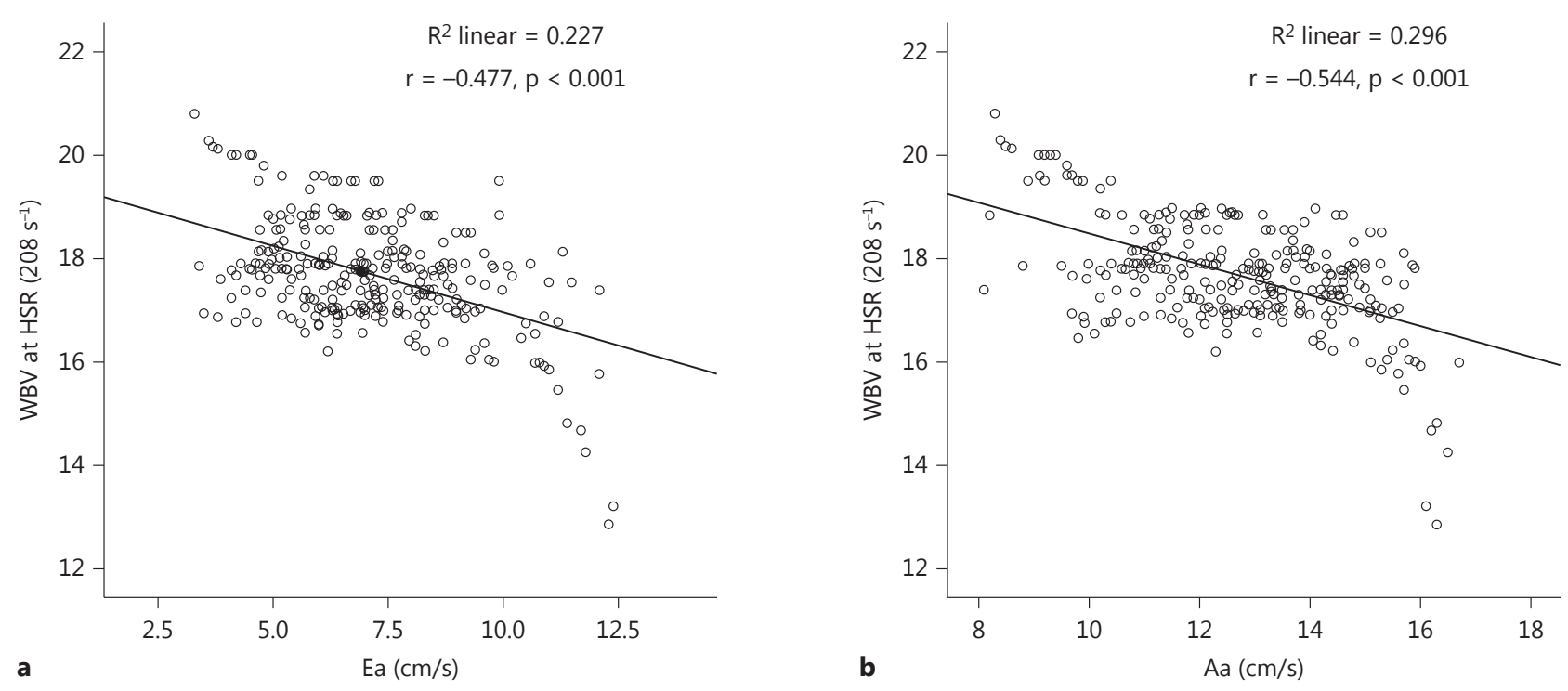

Fig. 1. Correlation between WBV at HSR with $\mathrm{Ea}(\mathbf{a})$ and $\mathrm{Aa}(\mathbf{b})$. Each dot represents 1 patient and the straight line represents the best fit obtained by linear regression analysis.

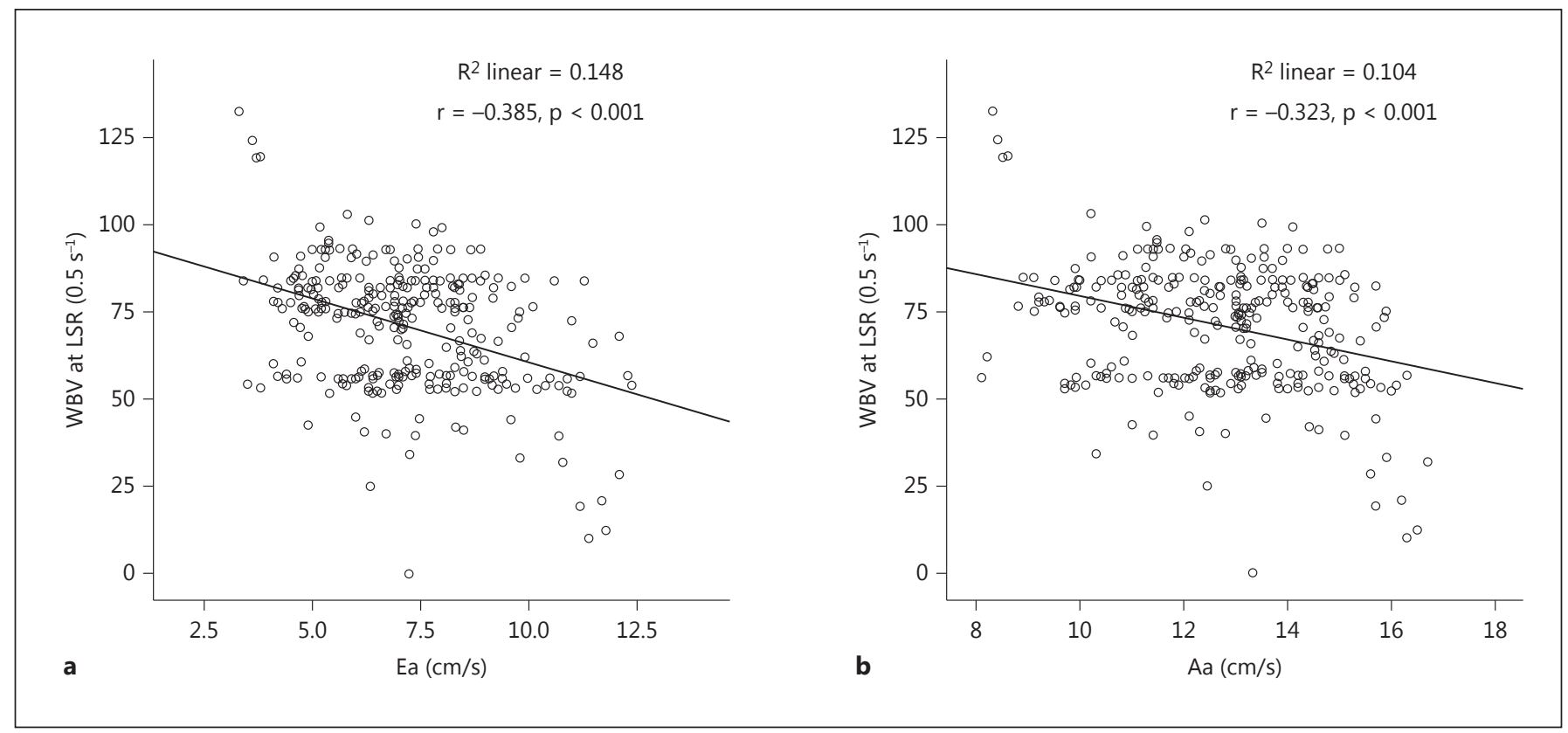

Fig. 2. Correlation between WBV at LSR with $\mathrm{Ea}(\mathbf{a})$ and $\mathrm{Aa}(\mathbf{b})$. Each dot represents 1 patient and the straight line represents the best fit obtained by linear regression analysis. 
Table 3. The effects of variables on MAC in univariate and multivariate logistic regression analysis

\begin{tabular}{|c|c|c|c|}
\hline Variable & OR & $95 \% \mathrm{CI}$ & $\mathrm{p}$ value \\
\hline \multicolumn{4}{|c|}{ Univariate logistic regression analysis } \\
\hline Age (years) & 1.037 & $0.971-1.108$ & 0.276 \\
\hline Male gender & 1.004 & $0.965-1.045$ & 0.842 \\
\hline Diabetes mellitus & 0.998 & $0.957-1.040$ & 0.914 \\
\hline Smoking & 1.199 & $0.469-1.1902$ & 0.705 \\
\hline Family history of CAD & 1.325 & $0.575-3.053$ & 0.508 \\
\hline Hypertension & 1.128 & $1.038-1.227$ & 0.005 \\
\hline Hyperlipidemia & 0.995 & $0.933-1.061$ & 0.878 \\
\hline LVEF & 1.024 & $0.963-1.088$ & 0.457 \\
\hline ASA & 0.988 & $0.922-1.060$ & 0.744 \\
\hline$\beta$-Blocker & 0.995 & $0.885-1.118$ & 0.928 \\
\hline ACE inhibitor & 1.057 & $0.958-1.167$ & 0.270 \\
\hline Statins & 1.005 & $0.988-1.023$ & 0.545 \\
\hline Ca-channel blocker & 0.998 & $0.990-1.006$ & 0.596 \\
\hline BMI & 0.971 & $0.930-1.014$ & 0.187 \\
\hline Hemoglobin & 1.038 & $0.974-1.107$ & 0.252 \\
\hline HCT & 0.859 & $0.727-1.015$ & 0.104 \\
\hline WBC & 0.931 & $0.831-1.043$ & 0.217 \\
\hline Neutrophils & 1.003 & $0.990-1.016$ & 0.657 \\
\hline Lymphocytes & 1.040 & $0.953-1.316$ & 0.380 \\
\hline Platelets & 1.003 & $0.987-1.019$ & 0.723 \\
\hline Glucose & 0.990 & $0.955-1.027$ & 0.604 \\
\hline Urea & 0.958 & $0.816-1.124$ & 0.597 \\
\hline Serum creatinine & 0.650 & $0.292-1.448$ & 0.292 \\
\hline Total protein & 1.036 & $0.949-1.130$ & 0.431 \\
\hline Albumin & 0.935 & $0.835-1.047$ & 0.245 \\
\hline Total cholesterol & 0.991 & $0.955-1.011$ & 0.503 \\
\hline LDL cholesterol & 1.003 & $0.995-1.011$ & 0.488 \\
\hline HDL cholesterol & 1.917 & $1.873-1.961$ & $<0.001$ \\
\hline Triglycerides & 0.933 & $0.832-1.045$ & 0.232 \\
\hline WBV at LSR & 1.329 & $1.213-1.445$ & $<0.001$ \\
\hline WBV at HSR & 3.941 & $2.474-5.662$ & $<0.001$ \\
\hline \multicolumn{4}{|c|}{ Multivariate logistic regression analysis } \\
\hline \multicolumn{4}{|l|}{ Model 1} \\
\hline Hypertension & 1.567 & $1.028-2.396$ & 0.045 \\
\hline HDL cholesterol & 1.841 & $1.608-2.108$ & 0.002 \\
\hline WBV at LSR & 1.071 & $1.052-1.091$ & $<0.001$ \\
\hline \multicolumn{4}{|l|}{ Model 2} \\
\hline Hypertension & 1.643 & $1.075-2.525$ & 0.039 \\
\hline HDL cholesterol & 1.606 & $1.039-1.400$ & 0.003 \\
\hline WBV at HSR & 3.118 & $2.202-4.415$ & $<0.001$ \\
\hline
\end{tabular}

$\mathrm{CAD}=$ Coronary artery disease LVEF = left ventricular ejection fraction; ASA = acetylsalicylic acid; $\mathrm{ACE}$ = angiotensin-converting enzyme; $\mathrm{ARB}=$ angiotensin receptor blocker; $\mathrm{Ca}=$ calcium; WBC = white blood cell count; LDL = low-density lipoprotein; $\mathrm{HDL}=$ high-density lipoprotein.

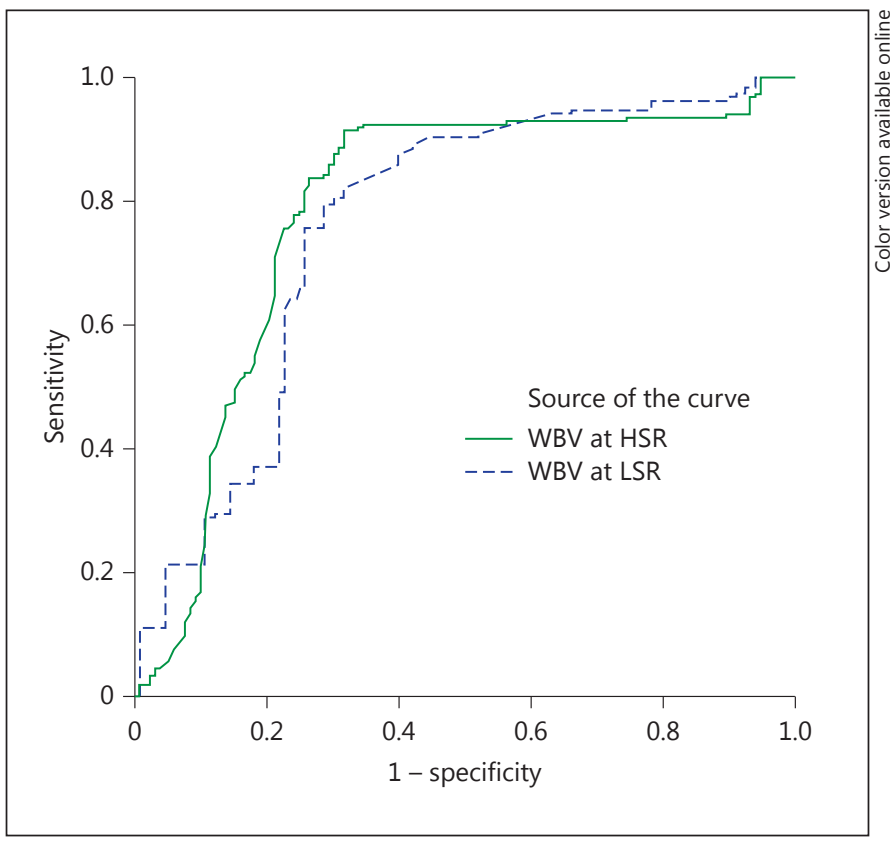

Fig. 3. The ROC curve analysis of WBV at HSR (green line; colors refer to the online version only) and LSR (blue line) for the prediction of MAC.

MAC is known as a chronic, noninflammatory, degenerative process of the fibrous structures of the mitral valve [11]. It is most commonly $[10,12]$ an incidental finding during a routine echocardiographic examination. Many studies have provided evidence that MAC is associated with established atherosclerotic risk factors, including older age, diabetes, hypertension, hyperlipidemia and renal dysfunction. Considering previous pathological studies $[11,12]$ and the fact that atherosclerosis and MAC have several common risk factors, it could be argued that MAC and atherosclerosis have the same etiology and could be a different form of the same pathophysiological condition $[13,14]$.

Previous data [15-18] have also shown that any alteration in hemorheological factors plays a central role during the atherosclerotic process. Various cardiovascular risk factors, including older age, increased body weight and carotid intimamedia thickness, are associated with changes in rheological parameters $[19,20]$. The alteration in WBV directly predicts endothelial shear stress, which is a key component during the atherosclerotic process, as increased WBV has been shown to lead to vascular remodeling and endothelial inflammation [21]. As a major component of Virchow's triad, WBV has been rarely studied because of the requirement for various pieces of equipment during its 
evaluation. However, de Simone et al. [7, 22] found and validated simple and noninvasive equations using total protein and HCT levels for the calculation of WBV at LSR and HSR. These extrapolation formulas have also been confirmed in large population studies [22-24].

As a form of atherosclerosis, endothelial disruption prompted by increased mechanical stress at the mitral valve annulus has been postulated as the initial step of MAC pathogenesis [6]. Sun et al. [3] investigated the ex vivo effect of fluid shear stress magnitude and frequency on early mechanisms of cardiovascular disease in porcine aortic valves and reported that the valve tissue was more sensitive to the changes in magnitude of shear stress. Therefore, we speculated that increased WBV might also aggravate endothelial disruption and inflammatory activation via increasing shear stress at the mitral valve annulus, resulting in MAC. Although both MAC and WBV are significantly associated with the development of atherosclerosis, there is no study in the literature assessing the association of WBV with the presence of MAC.

In our study, WBV values at HSR and LSR had a significant negative correlation with mitral annular motion velocities. Soeki et al. [5], who investigated mitral annular motion velocities by pulsed Doppler tissue echocardiography in patients with MAC, found decreased annular velocities and proposed that the severity of MAC correlated inversely with the annular Ea velocity. Concordant with this study, we found decreased mitral annular motion ve- locities in patients with MAC. On the grounds of these considerations, we postulate that a higher WBV may lead to greater limitation in mitral annular motion and to more severe MAC.

Our study had some limitations. First, there was no direct measurement of blood viscosity. However, correlation of the calculated WBV with the direct measurement of blood viscosity with a viscometer or the hemodynamic parameters associated with endothelial shear stress may increase the power of the results. Second, the parameters that may affect blood viscosity, including platelet and erythrocyte aggregability and rigidity, were not obtained.

\section{Conclusions}

Patients with MAC had significantly higher WBV, which independently predicted the presence of MAC. Additionally, WBV had a significant negative correlation with mitral annular motion velocities. These findings suggest a new insight into the importance of blood viscosity in mitral valvular mechanobiology.

\section{Disclosure Statement}

The authors declare no conflicts of interest.

\section{References}

-1 Fulkerson PK, Beaver BM, Auseon JC, et al: Calcification of the mitral annulus: etiology, clinical associations, complications and therapy. Am J Med 1979;66:967-977.

$\checkmark 2$ Jeon DS, Atar S, Brasch AV, et al: Association of mitral annulus calcification, aortic valve sclerosis and aortic root calcification with abnormal myocardial perfusion single photon emission tomography in subjects age $\leq 65$ years old. J Am Coll Cardiol 2001;38:19881993.

-3 Sun L, Rajamanna NM, Sucosky P: Defining the role of fluid shear stress in the expression of early signaling markers for calcific aortic valve disease. PLoS One 2013;8:e84433.

4 Adler Y, Fink N, Spector D, et al: Mitral annulus calcification - a window to diffuse atherosclerosis of the vascular system. Atherosclerosis 2001;155:1-8.

5 Soeki T, Fukuda N, Shinohara H, et al: Mitral inflow and mitral annular motion velocities in patients with mitral annular calcification: evaluation by pulsed Doppler echocardiography and pulsed Doppler tissue imaging. Eur J Echocardiogr 2002;3:128-134.

-6 Thubrikar MJ, Aouad J, Nolan SP: Patterns of calcific deposits in operatively excised stenotic or purely regurgitant aortic valves and their relation to mechanical stress. Am J Cardiol 1986;58:304-308.

$>7$ de Simone G, Devereux RB, Chinali M, et al: Association of blood pressure with blood viscosity in American Indians: the Strong Heart Study. Hypertension 2005;45:625-630.

8 Potpara TS, Vasiljevic ZM, Vujisic-Tesic BD, et al: Mitral annular calcification predicts cardiovascular morbidity and mortality in middle-aged patients with atrial fibrillation: the Belgrade Atrial Fibrillation Study. Chest 2011;140:902-910.

-9 Nwose EU, Richards RS: Whole blood viscosity extrapolation formula: note on appropriateness of units. North Am J Med Sci 2011;3: 384-386.
10 Sgorbini L, Scuteri A, Leggio M, et al: Association of mitral annulus calcification, aortic valve calcification with carotid intima media thickness. Cardiovasc Ultrasound 2004;2:19.

11 Korn D, Desanctis RW, Sell S: Massive calcification of the mitral annulus: a clinicopathological study of fourteen cases. N Engl J Med 1962;267:900-909.

12 Movahed M-R, Saito Y, Ahmadi-Kashani M, et al: Mitral annulus calcification is associated with valvular and cardiac structural abnormalities. Cardiovasc Ultrasound 2007;5:14.

13 Roberts WC: The senile cardiac calcification syndrome. Am J Cardiol 1986;58:572-574.

14 Durmus I, Karaman K, Öztürk S, et al: Mitral annular calcification is associated with pulse wave velocity but not with augmentation index. Med Princ Pract 2013;22:150-155.

15 Lowe GD, Lee AJ, Rumley A, et al: Blood viscosity and risk of cardiovascular events: the Edinburgh Artery Study. Br J Haematol 1997; 96:168-173. 
16 Kensey KR, Cho YI, Chang M: Effects of whole blood viscosity on atherogenesis. J Invasive Cardiol 1997;9:17-24.

17 Koenig W, Sund M, Filipiak B, et al: Plasma viscosity and the risk of coronary heart disease: results from the MONICA-Augsburg Cohort Study, 1984-1992. Arterioscler Thromb Vasc Biol 1998;18:768-772.

18 Sloop G, Holsworth RE Jr, Weidman JJ, et al: The role of chronic hyperviscosity in vascular disease. Ther Adv Cardiovasc Dis 2015;9:1925.
19 Carallo C, Irace C, De Franceschi MS, et al: The effect of aging on blood and plasma viscosity: an 11.6 years follow-up study. Clin Hemorheol Microcirc 2011;47:67-74.

20 Velcheva I, Antonova N, Titianova E, et al: Hemorheological parameters in correlation with the risk factors for carotid atherosclerosis. Clin Hemorheol Microcirc 2006;35:195198.

1 Silber HA, Bluemke DA, Ouyang P, et al: The relationship between vascular wall shear stress and flow-mediated dilation: endothelial function assessed by phase-contrast magnetic resonance angiography. J Am Coll Cardiol 2001;38:1859-1865.
2 de Simone G, Devereux RB, Chien S, et al: Relation of blood viscosity to demographic and physiologic variables and to cardiovascular risk factors in apparently normal adults. Circulation 1990;81:107-117.

23 Høieggen A, Fossum E, Moan A, et al: Whole-blood viscosity and the insulin-resistance syndrome. J Hypertens 1998;16:203210

24 Tamariz LJ, Young JH, Pankow JS, et al: Blood viscosity and hematocrit as risk factors for type 2 diabetes mellitus: the atherosclerosis risk in communities (ARIC) study. Am J Epidemiol 2008;168:1153-1160. 